\title{
Preface: Hydrogeology of shallow thermal systems
}

\author{
Diana M. Allen • Peter Bayer • Grant Ferguson • \\ Philipp Blum
}

Keywords Shallow thermal systems - Thermal conditions $\cdot$ Springs $\cdot$ Basins $\cdot$ Geo-exchange systems

\section{Introduction}

Hydrogeology plays an important role in the transfer of heat in geological systems. Large-scale variations in the permeability distribution (including the presence of fracture zones and faults) can significantly impact the coupled flow of heat and fluid (Smith and Chapman 1983). At the regional scale, groundwater flow can alter the heat distribution, depressing or enhancing thermal gradients in space and time, and carry heat over significant distances (Smith and Chapman 1983; Woodbury and Smith 1985; Molina-Giraldo et al. 2011). At smaller scales, groundwater flow can present challenges to the proper design of geoexchange systems and can limit the success of aquifer thermal energy storage (ATES) and borehole thermal energy storage (BTES) systems (e.g. Sauty et al. 1982a, b).

This special issue of Hydrogeology Journal presents a collection of articles that aim to advance understanding of

Received: 24 October 2013 / Accepted: 7 November 2013

Published online: 24 December 2013

(C) Springer-Verlag Berlin Heidelberg 2013

Published in the theme issue "Hydrogeology of Shallow Thermal Systems"

D. M. Allen (

Department of Earth Sciences, Simon Fraser University, Burnaby, BC, Canada V5A 1S6

e-mail: dallen@sfu.ca

P. Bayer

Department of Earth Sciences, ETH Zurich,

Sonneggstr. 5, 8092 Zurich, Switzerland

e-mail: bayer@erdw.ethz.ch

G. Ferguson

Department of Civil and Geological Engineering,

University of Saskatchewan, Saskatoon, SK, Canada S7N 5A9

e-mail: grant.ferguson@usask.ca

P. Blum

Institute for Applied Geosciences (AGW),

Karlsruhe Institute of Technology (KIT),

Kaiserstr. 12, 76131 Karlsruhe, Germany

e-mail: philipp.blum@kit.edu coupled hydrogeological and thermal processes over a range of spatial and temporal scales. The articles are broadly classified into three topics including springs (thermal and mineralized), basins (sedimentary and structure controlled), and geo-exchange systems. The issue focuses on novel fieldand modeling-based studies that have been carried out to study these shallow thermal systems, where hydrogeological processes play an active role in the redistribution of heat.

The decision to focus on shallow thermal systems as opposed to deep thermal systems was driven largely by a joint interest in highlighting low-to-moderate temperature (enthalpy) geothermal systems. This is not to say that hightemperature systems and/or deep systems are not considered herein, but rather that the emphasis is on lowertemperature systems that are often strongly influenced by groundwater flow in such a way as to alter the thermal regime, and that tend to exist at relatively shallow depth. Hebig et al. (2012) reviewed some of the early work that led to definitions of deep groundwater, both from the perspective of flow and geochemical characteristics. Most of the definitions of deep groundwater point to the absence of meteoric water (low tritium and a lack of bicarbonate) and slow circulation rates, but emphasize that the term deep groundwater is not bound to a defined depth below surface. The authors noted that such deep-lying aquifers have become important resources for the production of geothermal energy and alternative potable water sources, or for repositories (nuclear waste and $\mathrm{CO}_{2}$ ). Thus, the definition of shallow for this special issue is somewhat arbitrary, but is intended to capture hydrogeological systems at the critical zone near the Earth's surface, where groundwater flow actively influences thermal processes. This relatively shallow zone of the Earth's crust is where mixing of deep and shallow groundwater takes place, giving rise to complex geochemical and isotopic signatures. In addition, definitions of low, moderate and high-temperature geothermal energy are ambiguous in terms of temperature range. As a generality, high-temperature systems are most commonly used for power generation, and have been associated with the term geothermal. Moderate-to-lowtemperature systems tend to be used mostly for heating and/or cooling and are often recognized as geo-exchange systems. To avoid the problem of associating the content of the special issue with low-, moderate- or high-temperature systems, the term thermal is used in the issue's title.

A review of the peer-refereed literature suggests that there have been no journal special issues on groundwater 
(or hydrogeology) and geothermal (or thermal) systems, despite the important role that hydrogeology plays in thermal systems. A comprehensive review of geothermal energy technology is given by Barbier (2002), including the definition of heat flow and geothermal gradient, the types of geothermal fields, the geologic environment of geothermal energy, and the methods of exploration for geothermal resources including drilling and resource assessment. The focus, however, is high-temperature geothermal systems. Similarly, Ganguly and Kumar (2012) review mathematical principles related to geothermal reservoirs, and Kaya et al. (2011) summarize experience with reinjection worldwide, focusing on 91 electric-power producing geothermal fields. Bayer et al. (2013) provide a comprehensive overview of potential environmental effects of geothermal power generation. Goldscheider et al. (2010) review, in particular, the current knowledge on thermal water resources in carbonate rock aquifers, and Hebig et al. (2012) include some examples of geothermal reservoirs in their review of deep groundwater systems. Saar (2011) reviews the use of geothermal heat as a tracer of large-scale groundwater flow and as a means for determining permeability fields. Haehnlein et al. (2010) provide an overview of the current international legal status for the use of shallow geothermal energy, defined as occurring at depths shallower than $400 \mathrm{~m}$, based on the results of an international survey. The comprehensive textbook by Banks (2008) is also dedicated to low-enthalpy geothermal technologies. Finally, Stauffer et al. (2013) provide an overview of the stateof-the art in investigating and modelling flow and heat transport processes in shallow aquifers.

Many of the articles in this special issue employ several complimentary investigative approaches, including geochemical and isotopic characterization, hydrogeological conceptualization, and numerical simulation. Overall, the articles illustrate advances in different field and modeling methods of investigation as applied to thermal systems. The role of hydrogeology in controlling or influencing heat transport processes is particularly emphasized.

\section{Springs}

Springs, which issue from faults and fracture zones that extend to great depth, offer a window into deep subsurface thermal regimes. Thermal springs (warm and hot springs) normally are highly mineralized due to their deep origin and the long residence times of groundwater. Cold springs, however, can also issue at surface alongside thermal springs. This juxtaposition of thermally diverse waters points to the complexity of the hydrogeological system at depth.

Oftentimes, thermal springs are targeted during early phases of exploration for geothermal resources. Because of their easy access, geochemical and isotopic sampling is often carried out, and inferences are made on the nature of the geothermal reservoir at depth. Afsin et al. demonstrate the limitations of a geochemical and isotopic dataset for interpreting the characteristics of a thermal spring system in the Cappadocia region of Turkey. While some general inferences could be made on the geological origin of the spring waters, the relative ages of the waters, and the recharge to the system, mixing of deep geothermal waters with shallow meteoric waters is shown to be a dominant process that confounds the interpretation of the data. Seasonal differences in the $\delta^{18} \mathrm{O}$ and $\delta^{2} \mathrm{H}$ compositions of the water point to a rapid recharge environment, whereby mixing of recent meteoric groundwater with the geothermal waters is sufficiently fast to maintain seasonality in $\delta^{2} \mathrm{H}$. Groundwater age determinations from ${ }^{3} \mathrm{H}$ and ${ }^{14} \mathrm{C}$ were inconclusive due to mixing processes and a very high dissolved inorganic carbon. The study suggests that geochemical and isotopic data for thermal spring systems should be critically evaluated to identify whether mixing between groundwater sourced from local, intermediate and regional flow systems might be influencing the data.

Mayo et al. evaluate the degree to which selforganization explains the characteristics of the hydrothermal system in the Middle Fork of the Boise River of the Idaho batholith in the United States. Self-organization is a process whereby global order arises out of local interactions between the components of an initially disordered system. Within the context of a spring system, geochemical self-organization can occur in the fractured system as some fractures become more efficient due to mineral dissolution, which increases the aperture and, consequently, the permeability. Thus, over time, positive feedback occurs and even more flow occurs through these fractures. The final result is a system that is highly ordered. In this study, geochemical data gathering (for waters and rocks), inverse geochemical modeling, stable isotope data gathering, a geological structure analysis, and thermal flow area calculations were undertaken. Results suggest that recharge occurs in upland elevations and then circulates slowly to depth, ultimately ascending to surface where it encounters the damage zones associated with regional faults. Multiple hydrothermal systems rather than a single hydrodynamically connected one emerge, suggesting that self-organization occurs.

Maréchal et al. conducted a multidisciplinary study of a natural mineralized water system in southern France. The study included geological mapping and core logging, geo-electrical profiling, piezometric interpretation, pumping and interference tests, time series and statistical analysis, a MISO (multiple input single output) analysis, geochemical and isotopic characterization, and numerical modeling. From multiple lines of evidence, the study revealed compartmentalization and the presence of two permeable zones that extend to depth and that have orientations that are consistent with regional extensional structures. The hydrogeology of the system is largely controlled by leakage from overlying weathered material and the effects of compartmentalization. The $\mathrm{CO}_{2}$-rich mineralized waters originate at depth within marbles.

Vieira et al. explore the role that groundwater flow plays in controlling the distribution of thermal springs in 
the Paleozoic sedimentary basins of Brazil. Their numerical simulations indicate that groundwater flow velocities in excess of $1 \mathrm{~cm} /$ year, along flat lying aquifers, are potentially capable of masking thermal anomalies, and downward groundwater flow within recharge areas is shown to generate large zones with low temperatures in areas that would otherwise have high temperatures. They also explore the relative importance of vertical advection of groundwater in the tendency for convection through the use of the Peclet number and the critical Rayleigh number (as represented by the critical geothermal gradient). They examine the situation of upward or downward flow through confining units above the aquifer and how these vertical groundwater flows either promote the development of thermal springs or contribute to their absence.

\section{Basins}

Sedimentary and structurally controlled basins offer an interesting opportunity to develop geothermal resources. Although temperatures in these basins are often not high enough to support conventional geothermal power projects, temperatures often allow for electricity generation using binary-cycle power plants, and large direct-use developments are possible (e.g. Goldscheider et al. 2010). Highcapacity wells often can be completed in the aquifers present in these settings. In addition, large datasets are often available from the oil and gas industry as well as from regional groundwater monitoring. These data reduce the uncertainty and risk of developing these lower temperature resources, although little development has occurred to date.

Danis examines the utility of temperature measurements from groundwater monitoring networks in geothermal resource assessment. Shallow temperature measurements from the Sydney Basin, Australia, are analyzed to refine a geothermal resource assessment for this area. These data provide important constraints for geothermal models of this area and allow for a more accurate assessment of available geothermal resources in the upper few hundred meters of the Earth's crust. The usefulness of these temperature measurements is improved substantially after the effects of groundwater flow and past climates on subsurface heat flow are considered. Temperatures at the depths required for electricity generation are also constrained, but uncertainty remains high in this application $\left( \pm 40^{\circ} \mathrm{C}\right)$.

Pimentel and Hamza present regional-scale studies of Paleozoic sedimentary basins in the Amazon, Paraná and Parnaiba regions of South America. These are deep basins that extend to depths of up to $4 \mathrm{~km}$; hydrogeological data are sparse for the deeper portions of these basins. Bottom hole temperature (BHT) measurements from oil and gas wells are used to study groundwater flow in these basins. Recharge areas are characterized by lower temperatures than those at discharge areas, allowing for characterization of these systems. Large-scale disturbance of temperatures by groundwater flow has implications for geothermal development. Temperatures in the recharge area are underestimated by large amounts, if groundwater flow is not considered. Understanding regional groundwater flow can be a key to development of geothermal resources in such sedimentary basins.

Busby provides an overview of the geothermal potential of sedimentary basins in the United Kingdom. Oil and gas exploration provided the bulk of information for this assessment, which focused on direct use applications. Temperatures found in these environments would support widespread geothermal development without heat pump systems. Although, few permeability and porosity data are available from the deeper portions of these basins, values suggesting the existence of productive sandstone and limestone aquifers do exist. Despite a large inplace resource, current development has been limited due to economic and technological constraints.

Ferguson and Grasby outline the potential for electricity generation and direct use utilizing groundwater produced from the basal clastics in the Western Canada Sedimentary Basin. This analysis builds upon previous studies that have outlined the thermal regime of this basin by looking for insight into the hydrogeological properties of this geological unit. The bulk of this insight comes from injection wells that were completed into this unit by the oil and gas industry and potash mines. Many of these injection wells operate at very high rates. Geothermal wells could operate at similar rates, which would make geothermal power production feasible despite maximum temperatures of $\sim 100{ }^{\circ} \mathrm{C}$.

Mayrhofer et al. summarize the results of a comprehensive basin-wide study of the geochemistry of the Malm aquifer in the Bavarian Molasse Basin in southern Germany, where geothermal development is increasing. They demonstrate that the groundwater is of meteoric composition with a heterogeneous chemical composition that reflects a significant contribution of saline water that originates at shallow depth and infiltrates the deeper carbonate system. Very high sulfide and $\mathrm{H}_{2} \mathrm{~S}$ concentrations were measured, which were initially attributed to impregnation with $\mathrm{H}_{2} \mathrm{~S}$ gas. The highest sulfide concentrations in the groundwater and the highest $\mathrm{H}_{2} \mathrm{~S}$ concentrations in the gas phase were measured in the southern portion of the Molasse Basin. The results suggest that thermochemical sulfate reduction (TSR) is the primary $\mathrm{H}_{2} \mathrm{~S}$ generating process in the southern portion of the basin, because reservoir temperatures exceed the possible range for bacterial sulfate reduction (BSR). However, elsewhere in the basin to the north, BSR is considered the dominant $\mathrm{H}_{2} \mathrm{~S}$ producing mechanism. In addition, the study showed that samples collected during pumping tests conducted in the early phases of development were highly impacted by drilling activities. It was suggested that it might take up to 2 years of full operation to establish a hydrochemical equilibrium that would better represent the in situ conditions.

Finally, Pearson et al. created a series of models of the Tarunga low-temperature geothermal system in New Zealand. The models created are among the highestresolution low-temperature geothermal models ever developed. The models cover an area of $130 \mathrm{~km}$ by $70 \mathrm{~km}$ and extend to a depth of $2 \mathrm{~km}$. A comprehensive 
sensitivity analysis was conducted to explore a range of hydrogeological and geophysical frameworks that would fit the high-resolution temperature profiles from 17 wells. An additional 454 temperature measurements were used to assess qualitatively the fits of these models. The results suggested the presence of a significant heat source beneath Tarunga City, which agrees with the inferred geology of the area.

\section{Geo-exchange systems}

This special issue also includes articles on various types of geo-exchange systems such as ground source heat pump (GSHP) systems, groundwater heat pump (GWHP) systems, and aquifer thermal energy storage (ATES) systems. In general, aquifer heterogeneities influence the heat transport over a range of spatial scales and, therefore, can impact the design and operation of such systems. Most studies, however, treat the subsurface as homogeneous in models used to simulate flow and heat transport. While perhaps practical in terms of simplifying the model or avoiding costs associated with hydrogeological data collection, such approaches may underestimate the degree to which preferential flow can actually occur.

Hence, the article by Wagner et al. presents their experience with an active thermal tracer test (TTT), conducted in a shallow alluvial aquifer with high regional groundwater-flow velocity of around $5.5 \mathrm{~m} /$ day. Downgradient of a warm-water injection well, the propagation of a thermal plume was monitored, and coupled hydraulic-thermal transport was simulated in a numerical model. The motivation of this work was to explore the potential of temperature as an additional and often overlooked means to characterize aquifers. Injecting warmed (or cooled) water during an experiment of only a few hours can deliver worthwhile insight into preferential pathways and the general hydraulic properties of the subsurface. This is an alternative to long-term monitoring of naturally induced, often seasonal temperature variations such as in the vicinity of infiltrating rivers. The case study revealed substantial effects of aquifer heterogeneity on the monitored temperature signals. Thermal macrodispersion is identified as a crucial component of thermal transport in the studied sedimentary aquifer. By comparison with geophysical investigations at the same site, the same conclusions could be obtained on vertical heterogeneity and aquifer layering.

Dehkordi and Schincariol performed a sensitivity analysis using a numerical heat transport model of hypothetical GSHP systems. Various hydraulic and thermal input parameters such as groundwater flow velocity, thermal dispersion and thermal conductivity were varied to study the impact on the development of the thermal plume and outlet temperature of the borehole heat exchanger (BHE). The results show that for a successful design of a BHE, the knowledge of thermal conductivity and groundwater flow velocity is crucial. Hence, groundwater velocities $>0.1 \mathrm{~m} /$ day can significantly impact the size and shape of the thermal plumes and, therefore, should not be neglected for the design and operation of BHEs. Presently, site-specific characteristics of the subsurface are inadequately considered during the planning and design of small-scale GSHP systems (Blum et al. 2011). Only for larger-scale GSHP systems are thermal response tests (TRT) routinely applied to determine the effective thermal conductivity of the subsurface and to optimize the design and performance of the BHE (Stauffer et al. 2013).

Lo Russo et al. examine the applicability of parametric methods to support planning of open loop systems. This is motivated by the limited suitability of process based, computationally demanding numerical models for making fast predictions in a straightforward way. Parametric methods are especially suitable for preliminary analysis, for instance, before detailed planning or optimization of future installations. For their test site in Torino, Italy, an artificial neural network (ANN) is trained to predict the change of groundwater temperatures in the vicinity of a well doublet. The seasonal evolution of the thermal and hydraulic regimes in the heterogeneous sedimentary aquifer during operation of two 47-m deep wells are monitored and simulated by a numerical model. Observational and modeled data are utilized to develop the neural network, which is demonstrated to reliably predict temperatures at given downgradient distance in the aquifer. This work nicely reveals the potential of neural networks in the design of shallow geothermal systems. Here, the thermally affected zone from an open loop system is studied, but this may be expanded also to closed systems.

Besides the standard open and closed loop systems, which directly use the groundwater or the subsurface as an energy source, other energy sources are increasingly applied such as underground mine waters of flooded and abandoned mines (Watzlaf and Ackman 2006). Using a three-dimensional numerical heat transport model, Raymond and Therrien studied the optimum design of a geothermal district heating and cooling system for the Gaspé Mines in Murdochville, Canada. In their model, underground shafts and tunnels are represented as onedimensional elements whose flow and heat are superimposed on the three-dimensional porous medium. The model predictions show that the required heating load of the buildings on site can be sufficiently provided using a minimum operating flow rate of $68.4 \mathrm{~m}^{3} / \mathrm{h}$.

Furthermore, instead of only using underground mine water or groundwater as a source or a sink of energy, the subsurface is also becoming increasingly used as a storage medium. Bridger and Allen compare heat transport, storage and recovery in an ATES system for two representations of the geology at a site in British Columbia (Canada), layered and non-layered. Calibration to transient flow data (a pumping test) indicate that both models perform equally well, with minor differences between the simulated and measured responses. A heatinjection sensitivity simulation showed that, with the exception of vertical anisotropy and hydraulic gradient, 
the non-layered case is insensitive to the ranges of all thermal and hydraulic properties considered, compared to the layered case. Preferential flow along high permeability layers during injection simulations resulted in plume distortion and elongation with greater transport distances and, consequently, thermal breakthrough at the extraction well. The simulation results for the layered model were largely consistent with observed temperatures measured in monitoring wells at the site. The study results emphasize that incorporating geological heterogeneity into models of aquifer thermal energy storage (ATES) systems is important for representing preferential flow that might lead to premature thermal breakthrough at wells.

The work by Lee is dedicated to effects of regional groundwater flow on ATES. In fact, horizontal groundwater flow velocity can be expected to have substantial influence on the long-term development of thermal anomalies, their intensity and extent. In this study, groundwater well doublets used for seasonal heating, storage and cooling are simulated numerically for synthetic scenarios that are operated for 10 years of continuous injection and withdrawal. The scenarios span ranges of different injection water temperatures, interwell spacings, aquifer sizes and horizontal groundwater flow velocities. Analysis of these variable geometric and operational parameters demonstrates how the performance of ATES depends on the thermal interference between stored cold and warm thermal energy in the aquifer. A main determinant is shown to be the groundwater flow velocity and the general flow direction.

Sommer et al. studied the long-term thermal performance and the heat transport processes of an ATES system on the campus of Utrecht University in the Netherlands. The regional groundwater flow velocity in the studied aquifer is about $5 \mathrm{~m} /$ year. The system uses eight groundwater wells to provide heating and cooling for several office buildings. No thermal interference between the extraction and injection wells has been observed, yet. Using detailed well-field operational data, measured groundwater temperatures with distributed temperature sensing (DTS) and a numerical heat transport model, the successful storage and recovery of the thermal energy of the ATES system is demonstrated. The average thermal recovery is $82 \%$ for cold storage and $68 \%$ for heat storage; the differences in thermal recovery are mainly caused by aquifer heterogeneities.

Currently the vast majority of underground thermal energy storage systems (UTES) such as borehole thermal energy storage (BTES) and the previously described ATES systems, operate at low temperatures $<30{ }^{\circ} \mathrm{C}$ (Sanner et al. 2003; Diersch et al. 2011); although, the storage of higher temperatures has the advantage that the groundwater can be used directly for heating and no additional energy is necessary to operate the heat pumps. However, the current legal situation in many countries only allows a maximum injection temperature of $25{ }^{\circ} \mathrm{C}$ (Haehnlein et al. 2010). Furthermore, other associated environmental risks due to the operation of such systems also have to be considered (Bonte et al. 2011). For example, the use of higher injection temperatures could substantially impact and alter the groundwater ecosystem (Brielmann et al. 2009) and the hydrogeochemistry of the aquifer (Bonte et al. 2013). Hence, only a few moderateand high-temperature ATES are currently operational worldwide and few have been studied in detail like the system implemented for the German parliament building in Berlin (Kabus and Seibt 2000). Thus, the final study in this special issue, by Schout et al., considers a hightemperature (HT) ATES system. The study uses a numerical model to evaluate the key factors that influence the recovery efficiency of such HT-ATES systems with temperatures $>70{ }^{\circ} \mathrm{C}$. Using a Rayleigh-based method, two exponential relationships are proposed to estimate the recovery efficiency of HT-ATES systems. Nevertheless, more research is needed to comprehensively investigate and promote such high-temperature storage systems.

\section{In conclusion}

The collection of papers in this special issue describes the worldwide use of a variety of field data (hydrogeological, geochemical and thermal) and numerical modeling approaches for investigating how hydrogeology influences shallow thermal systems. Despite the range of topics considered (springs, basins and geo-exchange systems), two common conclusions emerge. First, aquifer heterogeneity, leading to variations in the distribution of porosity and permeability, flow compartmentalization, and preferential flow pathways, is a critical aspect for understanding coupled flow and heat transport. While over-complicating conceptual models must be avoided, if the hydrogeological system is over-simplified, there is a risk of failing to account for factors that might have a significant influence on key processes. Second, in geothermal systems, in particular, whether shallow or deep, high or low temperature, the magnitude of groundwater flow and the direction of flow dictate where mixing takes place and how much of an influence mixing processes will have on the chemical and thermal regimes. For example, mixing can confound the ability to interpret geochemical data and can suppresses evidence of geothermal resources by modifying thermal gradients. In order to advance understanding of these complex thermal systems and enable high levels of predictive capability, whether it be for evaluating potential for geothermal resource development, predicting the long-term sustainability of the geothermal resource, or designing efficient geo-exchange systems, the hydrogeology must be carefully studied.

\section{References}

Banks D (2008) An introduction to thermogeology: ground source heating and cooling. Wiley, Chichester, UK, $352 \mathrm{pp}$

Barbier E (2002) Geothermal energy technology and current status: an overview. Renew Sust Energ Rev 6(1-2):3-65 
Bayer P, Rybach L, Blum P, Brauchler R (2013) Review of life cycle environmental effects of geothermal power generation. Renew Sust Energ Rev 26:446-463

Blum P, Campillo G, Kölbel T (2011) Techno-economic and spatial analysis of vertical ground source heat pump systems in Germany. Energy 36:3002-3011

Bonte M, Stuyfzand PJ, Hulsmann A, Beelen PV (2011) Underground thermal energy storage: environmental risks and policy developments in the Netherlands and European Union. Ecol Soc 16(1):22

Bonte M, van Breukelen BM, Stuyfzand PJ (2013) Temperatureinduced impacts on groundwater quality and arsenic mobility in anoxic aquifer sediments used for both drinking water and shallow geothermal energy production. Water Res 47(14):5088-5100

Brielmann H, Griebler C, Schmidt SI, Michel R, Lueders T (2009) Effects of thermal energy discharge on shallow groundwater ecosystems. FEMS Microbiol Ecol 68:273-286

Diersch HJG, Bauer D, Heidemann W, Rühaak W, Schätzl P (2011) Finite element modeling of borehole heat exchanger systems: part 2. numerical simulation. Comput Geosci 37:1136-1147

Ganguly S, Kumar MSM (2012) Geothermal reservoirs: a brief review. J Geol Soc India 79(6):589-602

Goldscheider N, Madl-Szonyi J, Eross A, Schill E (2010) Review: Thermal water resources in carbonate rock aquifers. Hydrogeol J 18(6): 1303-1318

Haehnlein S, Bayer P, Blum P (2010) International legal status of the use of shallow geothermal energy. Renew Sustain Energ Rev 14(9):2611-2625

Hebig KH, Ito N, Scheytt T, Marui A (2012) Review: Deep groundwater research with a focus on Germany. Hydrogeol J 20(2):227-243

Kabus F, Seibt P (2000) Aquifer thermal energy storage for the Berlin Reichstag Building: new seat of the German Parliament.
In: Proceedings World Geothermal Congress 2000, Beppu Morioka, Japan, May 28-June 10, 2000, pp 3611-3615

Kaya E, Zarrouk SJ, O'Sullivan MJ (2011) Reinjection in geothermal fields: a review of worldwide experience. Renew Sustain Energ Rev 15(1):47-68

Molina-Giraldo N, Bayer P, Blum P, Cirpka OA (2011) Propagation of seasonal temperature signals into an aquifer upon bank infiltration. Ground Water 49(4):491-502

Saar MO (2011) Review: Geothermal heat as a tracer of large-scale groundwater flow and as a means to determine permeability fields. Hydrogeol J 19(1):31-52

Sanner B, Karytsas C, Mendrinos D, Rybach L (2003) Current status of ground source heat pumps and underground thermal energy storage in Europe. Geothermics 32:579-588

Sauty JP, Gringarten AC, Menjoz A, Landel PA (1982a) Sensible energy storage in aquifers: 1 . theoretical study. Water Resour Res 18(2):245-252

Sauty JP, Gringarten AC, Fabris H, Thiery D, Menjoz A, Landel PA (1982b) Sensible energy storage in aquifers: 2. field experiments and comparison with theoretical results. Water Resour Res 18(2):253-265

Smith L, Chapman DS (1983) On the thermal effects of groundwater flow: 1. regional scale systems. J Geophys Res 88(B1):593608

Stauffer F, Bayer P, Blum P, Molina-Giraldo N, Kinzelbach W (2013) Thermal use of shallow groundwater. CRC, Boca Raton, FL, $266 \mathrm{pp}$

Watzlaf GR, Ackman TE (2006) Underground mine water for heating and cooling using geothermal heat pump systems. Mine Water Environ 25(1):1-14

Woodbury AD, Smith L (1985) On the thermal effects of threedimensional groundwater flow. J Geophys Res Solid Earth 90(B1):759-767 